\title{
Transformando tias em professoras: contribuições do pensamento de Paulo Freire para o processo de profissionalização de quem "ousa ensinar"
}

\author{
Luiz Gustavo Bonatto Rufino*
}

\section{Resumo}

Esse trabalho se insere na temática do movimento de profissionalização do ensino tendo em vista a transformação do ofício docente em um trabalho profissional. Estabelecemos interlocuções com parte da obra de Paulo Freire, cujas contribuições apontam para a proeminência da compreensão do trabalho docente na perspectiva profissional. A partir de um ensaio teórico dividido em três partes, objetivamos analisar as possíveis contribuições do pensamento de Paulo Freire para a perspectiva da profissionalização do trabalho de professoras e professores e suas implicações para a transformação da prática pedagógica. Concluímos que o pensamento de Freire reforça a necessidade de se entender o trabalho profissional como elemento estruturador da ação educativa libertadora em sua complexidade e reflexividade, possibilitando o desenvolvimento da práxis contextualizada e transformadora da sociedade.

Palavras-chave: Paulo Freire; Profissionalização do Ensino; Saberes Docentes; Ação Educativa; Práxis.

Licenciado em Educação Física pela Universidade Estadual Paulista Júlio de Mesquita Filho, UNESP Rio Claro e em Pedagogia. Especialista em Docência do Ensino Superior, Mestre pelo Programa Interdisciplinar em Desenvolvimento Humano e Tecnologias e Doutor em Ciências da Motricidade. Prêmio Educador Nota 10 em 2019, com o projeto "Ressignificando as visões sobre o corpo”. E-mail: gustavo_rufino_6@hotmail.com 


\section{Transforming aunts in teachers: contributions from Paulo Freire's thought to the professionalization process of those who "dare to teach"}

\section{Abstract}

This study is based on the teaching professional movement thematic, searching to transforming teachers' work into a professional achievement. We seek to established interlocutions with part of Paulo Freire's work, whose contributions pointed to the prominence of the understanding of teaching work in a professional perspective. From a theoretical essay divided into three parts, we aim to analyze possible contributions of Paulo Freire's thought to the perspective of teachers' professionalizing and their implications for the transformation of pedagogical practice. We conclude that Freire's thinking reinforces the need to understand professional work as a structuring element of educational action for freedom in its complexity and reflexivity, enabling the development of contextualized and transformative praxis in our society.

Keywords: Paulo Freire; Teaching Professionalization; Teachers Knowledge; Pedagogical Action; Praxis.

\section{Transformando tías en maestras: contribuciones del pensamiento de Paulo Freire al proceso de profesionalización de aquellos que "se atreven a enseñar"}

\section{Resumén}

Este trabajo se basa en la temática del movimiento de profesionalización docente con miras a transformar la actividad de los docentes en un trabajo profesional. Establecimos interlocuciones con parte del trabajo de Paulo Freire, cuyas contribuciones apuntan a la importancia de la comprensión del trabajo docente desde una perspectiva profesional. A partir de un ensayo teórico dividido en tres partes, nuestro objetivo es analizar las posibles contribuciones del pensamiento de Paulo Freire a la perspectiva de profesionalizar el trabajo de los docentes y sus implicaciones para la transformación de la práctica pedagógica. Concluimos que el pensamiento de Freire refuerza la necesidad de entender el trabajo profesional como un elemento estructurante de la acción educativa para la libertad en su 
complejidad y reflexividad, permitiendo el desarrollo de una praxis contextualizada y transformadora en nuestra sociedad.

Palabras-clave: Paulo Freire; Profesionalización de la Enseñanza; Conocimientos del Maestros; Acción Educativa; Praxis.

\section{Introdução: o processo de profissionalização do ofício docente: diálogos com Paulo Freire}

No decorrer do século XX, sobretudo a partir de meados da década de 1970, houve uma intensificação das proposições teóricas destinadas a compreender a importância de se profissionalizar o trabalho realizado por professores e professoras em todo o mundo. Tais iniciativas apresentavam como um de seus principais motes a ruptura paradigmática com a ideia da docência como uma atividade secundária, de menor importância social, que bastaria gostar ou ter "dom" ou que fosse uma ação de abnegação, quase vocacional.

Essas concepções, galgadas no constructo histórico da pedagogia ao longo do tempo, são representadas por Tardif (2013), por exemplo, de "idades do ensino", as quais compreendem, em um primeiro momento, a "idade da vocação", passando em um segundo momento pela "idade do ofício" e, finalmente, por um terceiro momento, intitulado "idade da profissão". Tardif (2013) ainda salienta que essa última idade se apresenta de forma pouco perene em muitos contextos (o Brasil entre eles), de modo que problematiza que, em se tratando do processo de profissionalização, temos dado "dois passos para a frente, três para trás".

Contemporaneamente ao longo do fortalecimento do que se tem denominado na literatura científica de "movimento de profissionalização do ensino", Paulo Freire construiu sua obra e deixou sua marca nos anais da história da pedagogia e do ensino de modo geral. Apesar de tal movimento representar uma ação iniciada em contextos anglófonos (HOLMES GROUP, 1986) e francófonos (TARDIF; LESSARD; LAHAYE, 2001), podemos considerar que Paulo Freire foi um contemporâneo de tal perspectiva e, em certa medida, até mesmo um influenciador de parte desses pressupostos. 
Florescendo de forma marcante a partir da década de 1970 e gerando frutificações até o presente momento, boa parte das ideias Freireanas tornaram-se elemento fulcral para se pensar a perspectiva da prática pedagógica e dos processos de ensino e aprendizagem escolar como intento profissional de educadores e educadoras ao redor do mundo. Essa é uma das razões que levou diversos autores que estudam a profissionalização do ensino a buscar apoio e referencial em Paulo Freire, a exemplo de Tardif (2012), entre inúmeros outros.

À primeira vista, partindo-se de uma leitura restrita e limitada da obra de Paulo Freire, é possível incorrer ao equívoco de classificá-lo como decorrente da "idade da vocação", momento no qual considerava-se que bastava ter "vocação", "dom", gostar e/ou amar o que faz, trazendo-se luz para um esforço abnegado e que não necessitava sequer de recursos financeiros para seu exercício. Tais equívocos advém de representações e leituras superficiais e que restringem os pressupostos de Freire aos momentos em que o autor aponta a necessidade de "amar" o ensino ou os alunos (FREIRE, 1996) e/ ou que discorre acerca da possibilidade de "vocação" (FREIRE, 1980) para o envolvimento efetivo dos professores com suas práticas, ou ainda que salienta a utopia e o sonho vinculado ao exercício cotidiano da docência (FREIRE, 2000), entre outros conceitos.

Todavia, a leitura atenta da obra de Paulo Freire e de toda sua complexa teia de conceituações e representações fortemente arraigadas com a ideia de liberdade, emancipação, educação popular, práxis e transformação social permite compreender que em sua fundamentação a ideia de se entender os professores como pessoas profissionais está no cerne de boa parte das problemáticas deliberadamente analisadas pelo autor. Em alguns textos, tal perspectiva é colocada ainda mais em evidência, a exemplo da obra "Professora sim, tia não: cartas a quem ousa ensinar" (FREIRE, 1993). Contudo, em diversos outros manuscritos, a concepção de profissão e profissionalização se torna menos latente e se apresenta de modo menos evidente, porém não menos importante. É o caso, por exemplo, da 
ideia de que ensinar é uma especificidade humana que exige além da segurança e generosidade, competência profissional (FREIRE, 1996). A imbrincada relação entre liberdade e autoridade no ser professor também ajuda a elucidar essa perspectiva (FREIRE; SHOR, 1986).

Nesse sentido, apesar de não ser uma das temáticas mais enfatizadas ao longo de sua extensa produção, pode-se considerar que a análise do processo de profissionalização do ofício docente perpassa boa parte dos ideais e utopias de Paulo Freire ao se compreender a pedagogia e a educação de modo geral. Todavia, em que pese a importância de tal intento, considera-se que a literatura não tem até o presente momento dado a devida atenção a essa compreensão. Desse modo, são poucos os trabalhos que procuraram relacionar o pensamento Freireano com a temática dos processos de profissionalização do ensino e suas implicações atuais.

Gadotti (2007), por exemplo, ao tecer uma ampla análise acerca de parte das obras de Paulo Freire, destaca, em diversos momentos, que a relação entre escola e professor deve ser constituída a partir da perspectiva profissional, dotando-os de competência e responsabilidade em suas ações. Segundo esse autor, a qualidade do ensino se fomenta à medida que se desenvolve a qualidade dos profissionais que exercem essa ação laboral em toda sua multiplicidade de sentidos de modo que a "desprofissionalização" do professor acaba por atingi-lo, sobretudo, como cidadão (GADOTTI, 2007).

Ao investigar o legado de Freire e tecer análises acerca da profissionalização do ofício docente, o professor Moacir Gadotti (2007) relembra ainda do tempo de Paulo Freire como administrador público, mais especificamente como Secretário de Educação do governo de Luiza Erundina na prefeitura de São Paulo. Segundo Gadotti (2007) Freire propôs uma série de ações políticas tendo em vista desenvolver a prática pedagógica e a formação dos educadores e educadoras, buscando garantir condições de trabalho e salariais adequadas e condizentes. Apesar dos desafios, pode-se compreender que a preocupação com a esfera profissional do ensino foi sem- 
pre um ponto a ser buscado por Paulo Freire em toda sua vida (GADOTTI, 2007).

Tendo em vista a proeminência e o vanguardismo do pensamento de Paulo Freire, bem como considerando a pertinência do momento atual no qual o trabalho docente tem sido alvo de constantes críticas e desvalorização, torna-se importante desenvolver propostas de interlocução entre os pensamentos desse autor e as perspectivas advindas das correntes ligadas à profissionalização docente. Uma vez que não existe neutralidade no processo educativo, como enfatiza Freire em diversas de suas obras, o esforço pelo enlace de compreensões acerca da visão do professor como um profissional dota-se de conotação política fundamental no contexto social do Brasil atualmente. Dessa ação política podemos vislumbrar novas propostas que demonstrem a efetividade da visão profissional ainda não constituída para a docência.

Assim, partindo-se da problematização constituída com a perspectiva da ação docente em seu direcionamento profissional, objetivamos com o presente ensaio analisar as possíveis contribuições do pensamento de Paulo Freire para a perspectiva da profissionalização do trabalho de professoras e professores e suas implicações para a transformação da prática pedagógica.

\section{De "tia" à "professora": o tornar-se profissional na perspectiva freireana}

Dentro da extensa produção intelectual desenvolvida por Paulo Freire ao longo de sua trajetória de vida, a figura do professor, em diversos momentos, ganhou relevo e centralidade. A partir de diferentes conceituações, a exemplo de "professor(a)", "animador(a)" e "educador(a)" (termos que mais aparecem quando o autor se refere a esses profissionais), Freire buscou desenvolver um olhar que evidenciasse a humanização dentro da prática educativa por meio da dialogicidade, valorizando questões como a relação entre professores e alunos, e a compreensão do contexto como forma de transformação social. Seja na relação direta nos ciclos de cultura, 
seja na atuação política na busca por melhores condições de atuação profissional, o professor, consciente de sua não neutralidade, deve propiciar possibilidades concretas e efetivas de desenvolvimento da "leitura do mundo" e, a partir dela, do exercício de conscientização para que seja possível a transformação social na relação entre opressores e oprimidos.

Para isso, Freire apresenta uma capacidade de escrita e articulação das ideias ímpar. Mais do que isso, sua escrita é desencadeadora de uma série de reflexões cruciais para se pensar a educação popular e a pedagogia de forma geral e, refletindo-se sobre isso, pensar o próprio mundo (uma vez que a educação não acontece à revelia do mundo excludente e opressor em que vivemos). No caso do livro "Professora sim, tia não: cartas a quem ousa ensinar" (FREIRE, 1993), por exemplo, o autor deixa claro que esse encadeamento de ideias está intrinsecamente articulado com sua obra logo antecessora, "Pedagogia da Esperança" (FREIRE, 1992). Esta, por sua vez, é uma releitura envolvente de seu livro mais impactante, "Pedagogia do Oprimido" (FREIRE, 1982), possivelmente uma das obras mais traduzidas e importantes do século XX no cenário da educação mundial. Parte das análises aprofundadas nessa obra de alcance global, por sua vez, foram inicialmente abordadas no livro "Educação Como Prática de Liberdade" (FREIRE, 1967). Enfim, a cada texto e em cada livro, novas compreensões somam-se às ideias cruciais que, em seu conjunto, demonstram a robustez desse autor cuja "presença no mundo e com o mundo" é absolutamente marcante.

Analisando-se parte dessa extensa obra, podemos compreender que ora de forma mais direta, ora de modo indireto, Paulo Freire aborda de forma consolidada a temática da profissionalização do ensino. Isso se dá, grosso modo, ao menos em três níveis. O primeiro representa o compromisso ético e histórico que o docente precisa desenvolver para exercer seu trabalho e, dessa forma, apresenta-se como um dos pilares de sustentação da teoria da ação educativa proposta por Freire. Em suma, a educação bancária (FREIRE, 1982) caminha na contramão de uma visão profissio- 
nal de docência ao inviabilizar o exercício efetivo do compromisso ético e histórico do educador frente à conjuntura de desigualdade social presente no mundo.

O segundo aspecto advindo das ideias de Freire que nos permite elucidar a necessidade de uma visão profissional para a prática pedagógica do professor alicerça-se na compreensão humanista por detrás da relação entre professor(a) e alunos, educador(a) e educandos. Assim, a perspectiva dialógica e de valorização dos saberes de todos os atores sociais que aprendem e apreendem em comunhão, reverbera em uma ação profissional de sustentação do trabalho por meio das relações advindas do próprio trabalho. Um exemplo dessa perspectiva relacional que estrutura a ação profissional do professor para Freire se refere ao seu amplo debate acerca do conceito de autoridade docente (FREIRE, 1996), fundamental para sua postura e prática cotidiana, mas que não deve se confundir com autoritarismo que nega o caráter humanizador da práxis educativa.

O terceiro aspecto que podemos considerar contido na obra de Paulo Freire e que permite uma apropriação para o conceito de profissionalização docente se refere ao caráter político da prática educativa. Mais especificamente, o professor para Freire é membro de um coletivo o qual, em seu conjunto, apresenta grande poder de decisão sobre seu trabalho, apesar de ser muitas vezes desvalorizado pela esfera daqueles que estão no poder (FREIRE, 1993). Essa ideia caminha em consonância com as perspectivas da sociologia das profissões a qual, entre outras coisas, reforça a consideração de que a consolidação profissional se dá na capacidade de tomada de decisão de todos os membros inseridos nessa ocupação, os quais apresentam força e engajamento enquanto grupo ocupacional (FREIDSON, 1998). É no poder da coletividade e do trabalho em grupo que a profissão de professor se constitui e, dessa forma, tamanha é a relevância dada por Freire para a perspectiva do trabalho coletivo, colaborativo e participativo.

Em suma, podemos compreender que Paulo Freire é signatário de um importante movimento no campo educativo de ruptura 
com visões ultrapassadas que comparam o professor e a professora (sobretudo da educação infantil e dos primeiros anos do ensino fundamental) com algum ente familiar, mais especificamente a partir do uso irrestrito propagado da adjetivação "tio" ou "tia". Por detrás dessa conotação familiar esconde-se um processo de desprofissionalização do trabalho docente, o qual passa a se caracterizar como um ato benevolente, vocacional ou mesmo pouco dotado de importância para as políticas educativas, para a esfera do debate público e para a sociedade de forma geral. Nesse sentido, o autor assinala:

A tarefa de ensinar é uma tarefa profissional que, no entanto, exige amorosidade, criatividade, competência científica, mas recusa a estreiteza cientificista, que exige a capacidade de brigar pela liberdade sem a qual a própria tarefa fenece (FREIRE, 1993, p. 10).

Ainda segundo Freire (1993), a separação da compreensão da professora como "tia" se faz fundamental à medida que tal visão deslegitima o exercício profissional de um grande contingente de trabalhadores envolvidos no campo do ensino escolar. Travestido por essa concepção, historicamente, políticas públicas buscaram desvalorizar a docência e aqueles que a exercem, considerando-a como uma atividade de menor importância, exercida por "tios e tias" e não por profissionais. Para o autor:

Ensinar é profissão que envolve certa tarefa, certa militância, certa especificidade no seu cumprimento enquanto ser tia é viver uma relação de parentesco. Ser professora implica assumir uma profissão enquanto não se é tia por profissão. Se pode ser tio ou tia geograficamente ou afetivamente distante dos sobrinhos, mas não se pode ser autenticamente professo$\mathrm{ra}$, mesmo num trabalho a longa distância, "longe" dos alunos (FREIRE, 1993, p. 11, grifo nosso).

A ideia de se reforçar a profissionalidade docente nos idos do início da década de 1990 é, por si, um ato revolucionário que está em consonância inequívoca com o movimento de profissionalização do ensino. Assim, de forma autêntica e por meio de uma 
linguagem clara, precisa e fundamentalmente didática, Freire (1993) traça importantes análises que, em síntese, fundamenta a ação pedagógica dos professores e professoras dentro da perspectiva profissional, rompendo-se, assim, com um olhar vocacional ou interpretativo apenas da docência como um ofício. Além disso, a articulação teórica com conceitos apresentados em outros livros permite estender que tal importância dada à perspectiva da profissionalização docente foi um intento paulatinamente posto em debate pelo autor no decorrer de sua trajetória de vida.

Em caráter de "cartas" o livro "Professora sim, tia não" (FREIRE, 1993) problematiza, por um lado, uma série de questões diretamente relacionadas com o processo de profissionalização dos profissionais do magistério. Por outro lado, a obra também elucida o pensamento do autor frente a temas como as condições salariais e de formação dos educadores e de melhoria do ensino tendo em vista os conceitos fundamentais presentes em suas obras antecessoras retomando debates que reforçam seus ideais e utopias. Nas onze cartas que compõe a obra, adicionados com a introdução e as primeiras palavras, Paulo Freire apresenta em linguagem direta, clara e fortemente politizada, que só há espaço para o exercício da docência por meio da compreensão profissional daqueles que a exerce. Para isso, o autor aborda temas sensíveis a essa perspectiva, tal como o início na profissão (quinta carta), processo de significação e leitura do mundo (primeira carta), a relação entre medo e coragem no ato de ensinar (segunda carta), o processo de escolha pelo curso de magistério (atualmente pedagogia) (terceira carta), as qualidades indispensáveis aos professores progressistas (quarta carta), entre outras questões importantes (FREIRE, 1993).

Ainda segundo Freire (1993), é justamente na luta pelo desenvolvimento profissional e por melhores condições de trabalho que se forja a legitimidade da profissão de professor e professora. $\mathrm{O}$ autor exemplifica essa perspectiva por meio de um arsenal de iniciativas possíveis tal como a importância dos sindicatos, de manifestações e de instituições de greves, além de problematizar a com- 
paração dos professores com outros servidores públicos (a exemplo dos procuradores). Para o autor é por meio da luta por melhores condições que se institui a postura profissional frente a dimensão de "tia" que historicamente constituiu as representações advindas das políticas públicas de educação. Esperar que mudanças partam de entes que detém o monopólio do poder é uma visão um tanto quanto ingênua e "passiva" frente ao mundo (FREIRE, 1993).

O projeto de profissionalização pensado por Paulo Freire no decorrer de suas obras nos ilustra que toda e qualquer iniciativa pensada para a superação do status quo e das desigualdades sociais por meio da educação só tem vez se rompermos com visões ultrapassadas e reforçarmos de modo militante em prol das conquistas na esfera da profissionalidade docente. A alteração do nome "tia" para "professora" é, conforme ilustrado pelo autor, muito mais que apenas uma questão semântica. Por detrás dela há todo um constructo que demonstra outra representação de mundo, um mundo no qual o ser profissional constitui a própria identidade dos professores e professoras. O autor arremata: "O mundo afetivo desse sem-número de crianças é roto, quase esfarelado, vidraça estilhaçada. Por isso mesmo essas crianças precisam de professoras e de professores profissionalmente competentes e amorosos e não de puros tios e de tias" (FREIRE, 1993, p. 69).

\section{Repensando a profissão docente no século XXI: possíveis contribuições e interlocuções com $\mathrm{o}$ pensamento de Paulo Freire}

Conforme ressaltamos, o intento de se pensar os professores como profissionais tem sido uma construção social historicamente permeada por muitas lutas e disputas. Em diversos contextos sociais ainda é proeminente as visões que descaracterizam a importância da docência e/ou a deslegitima socialmente frente à outras ocupações mais elitizadas. A velha redoma da máxima: "mas você trabalha ou só dá aula?" é mais presente no imaginário social cotidiano do que podemos pressupor. 
Com efeito, foi preciso um grande esforço acadêmico, político e social para que se pudesse questionar as compreensões errôneas e buscar valorizar o trabalho docente e a emergência de uma cultura profissional. Esse intenso processo, cujas repercussões atravessam a contemporaneidade, é intitulado de "movimento pela profissionalização do ensino".

Segundo Tardif (2013), apesar do processo de profissionalização do ensino representar uma tendência no ocidente no decorrer do século XX, ela foi intensificada a partir da década de 1980, por meio de um conjunto de ações advindas de diversos países. Nessa conjuntura, destaca-se a elaboração do relatório escrito por acadêmicos de universidades norte-americanas, intitulado "Holmes Group” (1986). Esse documento pode ser considerado um marco dentro do movimento de profissionalização do ensino ao destacar, entre outras coisas, a necessidade de criação de estratégias para se desenvolver a formação de professores a partir da fundamentação de um amplo conjunto de conhecimentos e saberes compatível com as necessidades dessa profissão.

Em sua idealização, o movimento de profissionalização do ensino, conforme salienta Tardif (2013) apresentou ao menos três grandes objetivos: 1) melhorar o desempenho do sistema educativo; 2) passar do ofício à profissão; e, 3) construir uma base de conhecimentos sólida para o ensino. Segundo o autor, apesar de avanços terem sido encontrados, o desenvolvimento da profissionalização não tem sido apresentado de forma linear, de modo que as políticas atuais apresentam uma estagnação e até mesmo uma retração em sua transformação de ofício à profissão (TARDIF, 2013).

Entre os avanços possíveis por meio da profissionalização do ensino, desataca-se a valorização profissional, o maior reconhecimento financeiro, a melhora nas condições de trabalho, o desenvolvimento da autonomia profissional, bem como a consolidação de um conjunto de conhecimentos considerados como base para a atividade profissional da docência. Essa última questão é particularmente fundamental para esse movimento, pois reconhece que uma 
profissão legitimada socialmente necessita de um corpo de conhecimentos e saberes que a diferencie e distinga das demais. O relatório apresentado pelo "Holmes Group” já apontava que os professores carecem de saberes profissionais fundamentais (HOLMES GROUP, 1986). Gauthier et al. (2013), por sua vez, afirmam que a definição de um conjunto de saberes válidos para a prática profissional dos professores, além de permitir a profissionalização do ensino, é importante pois possibilita uma melhor orientação daqueles que a exercerão, ou seja, apresenta implicações fundamentais para a formação de professores.

Para Gauthier et al. (2013), a determinação desse repertório específico de conhecimentos deve ser feita a partir da análise do trabalho docente. De acordo com os autores é preciso superar as visões que relacionam o ensino tanto como um "ofício sem saberes" (galgado na reprodução por tentativa erro), quanto como de "saberes sem ofício" (fundado no aplicacionismo das ciências da educação). Para isso, é preciso compreendê-lo como um "fficio feito de saberes", valorizando o trabalho dos professores como núcleo gerador de sentidos de sua profissão.

Sendo assim, de acordo com Gauthier et al. (2013), embora muitas pesquisas de diferentes vertentes têm sido realizadas com relação aos conhecimentos de base para o ensino, a determinação desse repertório específico deve ser feita a partir da análise do trabalho docente. Ora, uma vez que este repertório de saberes é utilizado na prática pelos professores, as análises devem ser realizadas a partir do que os docentes realmente fazem ao longo de suas ações profissionais (TARDIF, 2012), ou seja, é preciso desvelar os seus saberes.

Emerge, desse contexto, a compreensão de saberes docentes, entendidos como uma possibilidade de representação dos conhecimentos de base para a profissão dos professores. Tardif (2012) compreende os saberes em um sentido amplo, no qual estão representados os conhecimentos, as práticas, as competências e as habilidades necessárias para o exercício profissional da docência. Busca-se assim superar a visão de que para ensinar é preciso apenas de conhecimen- 
tos científicos. De acordo com o autor, os saberes podem ser considerados como "formado pelo amálgama, mais ou menos, coerente, de saberes oriundos da formação profissional e de saberes disciplinares, curriculares e experienciais" (TARDIF, 2012, p. 36).

Podemos considerar que a fundamentação de saberes que constituam-se de base para a docência e que não fundamentam-se apenas nos conhecimentos científicos, mas levam também em consideração as experiências dos professores, suas histórias de vida, os saberes da tradição pedagógica e aqueles advindos da própria prática são contribuições nefrálgicas de Paulo Freire e seu legado no campo educativo. Conceitos como o de "ser cognoscente" e da "capacidade ontológica" apresentados por Freire em diversas obras materializam essa compreensão de saberes como forma de legitimação da profissão de professor. $\mathrm{O}$ autor destaca:

A educação é permanente não porque certa linha ideológica ou certa posição político ou certo interesse econômico o exijam. A educação é permanente na razão, de um lado, da finitude do ser humano, de outro, da consciência que ele tem de finitude. Mais ainda, pelo fato de, ao longo da história, ter incorporado à sua natureza não apenas saber que vivia, mas saber que sabia e, assim, saber que podia saber mais. A educação e a formação permanente se fundam aí (FREIRE, 2001, p. 20, grifos do autor).

Um exemplo bastante pertinente apresentado por Freire ao abordar a temática dos saberes dos professores é o livro "Pedagogia da Autonomia: saberes necessários à prática educativa” (FREIRE, 1996), a última de suas obras publicada em vida. Nesse texto o autor aborda uma série de reflexões a respeito dos saberes dos professores e avança no debate da profissionalização à medida em que não restringe a compreensão de saberes ao campo científico e/ou tecnicista, mas apresenta uma diversidade de saberes que se fundamentam no exercício da prática profissional, dotando de importância a relação entre docência e discência, na não transferência de conhecimento e na especificidade humana vinculada ao ato de ensinar. 
Tamanha é a pertinência da obra de Paulo Freire que Tardif (2012), por exemplo, reconheceu esse papel ao cita-lo como um dos expoentes da pedagogia crítica que busca compreender os saberes dos professores levando-se em consideração seu trabalho, sua história, sua vida. Segundo Tardif (2012), Paulo Freire é signatário da perspectiva que privilegia uma visão ético-política da profissão, concebendo o ensino como uma ação ética ou política (educação como luta política e emancipação coletiva).

Em suma, a compreensão dos saberes docentes permite maior apropriação das relações encontradas durante a prática profissional. Entretanto, se na prática, como apontou Schön (1983), emergem uma série de problemas cujas respostas precisam ser oferecidas no momento em que acontecem e que, na grande maioria das vezes, fogem aos pressupostos científicos, os saberes docentes permitem compreender a fonte desse conjunto de ações, valorizando, sobremaneira, o trabalho dos professores.

Para isso, é necessário outro tipo de racionalidade, uma vez que a racionalidade técnica, baseada no "aplicacionismo" de teorias não considera os professores como produtores de saberes, mas apenas como aplicadores de teorias científicas. A perspectiva dos saberes docentes, por sua vez, compreende que a prática profissional é lugar de mobilização de um conjunto de saberes provenientes de diferentes fontes que produzem e geram novos conhecimentos. Dessa forma, ao pensar a docência nos dias de hoje deve-se valorizar os contextos de prática profissional dos professores, compreendendo as fontes que geram os saberes profissionais, bem como é fundamental repensar a formação de professores, para que ela seja mais adequada no que se refere à valorização da profissão docente.

A compreensão de prática não em uma perspectiva aplicacionista, mas como lócus de produção e transformação de saberes é outra grande contribuição de Paulo Freire para a temática da profissionalização. Ao romper com uma visão bancária de ensino e valorizar a práxis dando-a relevo centralizador dentro do processo educativo, Freire aponta para uma perspectiva de que a prática pro- 
fissional é fundamental para o tornar-se professor, permitindo-o desenvolver saberes que o constitua profissionalmente ao longo do tempo. Tamanha é a pertinência do conceito de prática para o autor que ele salienta:

A prática educativa, pelo contrário, é algo muito sério. Lidamos com gente, com crianças, adolescentes ou adultos. Participamos de sua formação. Ajudamo-los ou os prejudicamos nesta busca. Estamos intrinsecamente a eles ligados no seu processo de conhecimento. Podemos concorrer com nossa incompetência, má preparação, irresponsabilidade, para o seu fracasso. Mas podemos, também, com nossa responsabilidade, preparo científico e gosto do ensino, com nossa seriedade e testemunho de luta contra as injustiças, contribuir para que os educandos vão se tornando presenças marcantes no mundo (FREIRE, 1993, p. 32, grifo do autor).

Para que a prática ganhe centralidade formativa e constituidora de saberes Freire reforça a importância da reflexão como eixo central da constituição profissional na docência. Portanto, não se trata de "qualquer" prática, muito menos de uma atividade roteirizada e/ou mecanizada. De fato, a ideia de reflexão sobre a prática é central no pensamento desse autor, pois possibilita o professor compreender o que faz e, a partir disso, procurar transformar o que faz e, assim, transformar a si mesmo enquanto ser no mundo. Para Freire (1996, p. 22): “a reflexão crítica sobre a prática se torna uma exigência da relação Teoria/Prática sem a qual a teoria pode ir virando blablablá e a prática, ativismo".

Por fim, assumindo-se da profissionalização do ensino como uma visão teleológica que aponta uma direção para a docência, a ideia de formação ganha destaque. Isso se dá porque, via de regra, uma profissão regulamentada e socialmente reconhecida apresenta sólida formação (preferencialmente em nível superior). $\mathrm{O}$ ensino vem, ao longo dos anos, buscando consolidar-se nessa direção. Paulo Freire, por sua vez, em diversas de suas obras contribuiu com esse olhar, frisando que a ideia de formação é um ponto central para a constituição profissional do professor. 
Segundo Freire, a ideia de formação apresenta contornos mais amplos que caminham para além da formação inicial (também reconhecida como importante para o autor). O autor aborda muito o conceito de formação permanente do educador à medida que formação inicial e processos de formação continuada, inclusive em serviço e advindos da própria prática e das trocas coletivas cotidianas com os pares, fazem com que o professor venha se constituindo profissionalmente por meio de suas experiências e de suas reflexões sobre elas. Por meio do desenvolvimento da "curiosidade epistemológica”, Freire (1993) assevera que a formação permanente do educador deve possibilitar a ele distanciar-se momentaneamente de sua prática para, no contexto teórico, buscar elementos e ferramentas que o ajude a transformar a sua prática. Ainda para o autor:

tão importante quanto as outras e que já encerra em si o exercício de um direito, exigirem, brigando por sua efetivação, sua formação permanente autêntica - a que se funda na experiência de viver a tensão dialética entre teoria e prática. Pensar a prática enquanto a melhor maneira de aperfeiçoar a prática. Pensar a prática através de que se vai reconhecendo a teoria nela embutida. A avaliação da prática como caminho de formação teórica e não como instrumento de mera recriminação da professora (FREIRE, 1993, p. 11).

Nesse sentido, a docência não deve ser compreendia por Freire como uma atividade profissional que "qualquer pessoa" é capaz de desenvolver, independente de sua capacidade ou competência. Pelo contrário, é fundamental que o educador se forme, permanentemente, para isso, exigindo-se capacidade de atuação profissional em contextos desafiantes e desiguais e, também, formação adequada para se exercer essa atividade profissional. Para o autor:

O fato, porém, de que ensinar ensina o ensinante a ensinar um certo conteúdo não deve significar, de modo algum, que o ensinante se aventure a ensinar sem competência para fazê-lo. Não o autoriza a ensinar o que não sabe. A responsabilidade ética, política e profissional do ensinante lhe colocam o dever de se preparar, de se capacitar, de se formar antes mesmo 
de iniciar sua atividade docente. Esta atividade exige que sua preparação, sua capacitação, sua formação se tornem processos permanentes. Sua experiência docente, se bem percebida e bem vivida, vai deixando claro que ela requer uma formação permanente do ensinante. Formação que se funda na análise crítica de sua prática (FREIRE, 1993, p. 19).

Freire reconhece, no entanto, que as políticas públicas que envolvem o trabalho dos professores e as representações sociais propostas pelos grupos que detém o monopólio do poder, dificultam, sobremaneira, essa constituição profissional. Assim, reconhecer tais dificuldades não significa colocar-se à margem da possibilidade de transformação da perspectiva profissional para o ensino. A postura de esperançar por transformações e a visão de sonhos e utopias preconizada por esse autor são elementos chaves. Nesse sentido, utopia não se assume como um "não lugar" para Freire, mas como um horizonte no qual o processo de conscientização e de leitura crítica do mundo permite com que se chegue (FREIRE, 1980). Em resumo, consideramos que apenas o processo de profissionalização é capaz de possibilitar efetivamente que tais análises e caracterizações propostas por Paulo Freire sejam de fato desenvolvidas. É na idade da profissão que o professor descrito por Freire exerce seu trabalho e é por meio da postura profissional que ele pode transformar a realidade social.

\section{Considerações finais: ninguém nasce educador ou marcado para ser educador}

Inserido na temática da profissionalização do ensino e, tendo como mote e inspiração parte dos pensamentos de Paulo Freire acerca desse campo, nos propusemos estabelecer alguns apontamentos que, longe de serem únicos e inequívocos, apresentam ao menos alguns direcionamentos que podem auxiliar no aprofundamento desse tema. Desse modo, o presente ensaio objetivou analisar as possíveis contribuições do pensamento de Paulo Freire para a perspectiva da profissionalização do trabalho de professoras e professores e suas implicações para a transformação da prática pedagógica. 
Conforme analisado, boa parte dos conceitos e análises propostos por Paulo Freire no decorrer de sua extensa produção teórica pode ser vinculado à perspectiva da profissionalização do ensino. Reconhece-se, evidentemente, que o autor não participou ativamente do denominado "movimento pela profissionalização do ensino" em sua origem, haja vista que tal empreendimento se desenvolveu sobre outros marcos teóricos e em outros contextos de intervenção. Apesar disso, sua obra influenciou diversos autores que tem reforçado a ideia da profissionalização da docência como elemento fundamental de nossa realidade.

Na obra "A Educação na Cidade" (FREIRE, 1991), em caráter de entrevista, publicada durante o exercício do cargo de Secretário de Educação da capital paulista, Paulo Freire apresenta o que é possivelmente uma de suas frases mais emblemáticas a respeito da importância da profissionalização do ensino tendo em vista a ruptura com a "idade da vocação". Nas palavras do autor: "Ninguém começa a ser educador numa certa terça-feira às quatro horas da tarde. Ninguém nasce educador ou marcado para ser educador. A gente se faz educador, a gente se forma, como educador, permanentemente, na prática e na reflexão sobre a prática" (FREIRE, 1991, p. 58).

Justamente por ser inacabado (incompleto, inconcluso) é que o ser humano vai se constituindo ao longo de sua história. Essa vocação ontológica preconizada por Freire, possibilita o processo de humanização. Uma vez que o professor é parte integrante dessa realidade social, ele também é concebido como um ser em constante processo de humanização. O professor não "nasceu" pronto para ensinar e nem se tornou pronto apenas por meio de seu curso de formação. De fato, ele se constitui permanentemente por meio de sua prática a partir da reflexão sobre a prática e por meio do desenvolvimento de experiências alicerçadas no aspecto relacional com os alunos e com os demais colegas também membros dessa mesma profissão. Ora, é no devir que o professor se constitui permanentemente.

Nesse sentido, os aspectos analisados no decorrer desse trabalho possibilitam ilustrar a importância dada à profissionalização 
do ensino dentro do pensamento Freireano. A compreensão de Paulo Freire acerca de temas como os saberes dos professores, a práxis, a prática e a reflexão sobre a prática e a formação são aspectos que ilustram tal relevância dada a essa temática para esse autor.

Ao buscar romper com a visão "inatista" de que pessoas "nascem" para ensinar, Paulo Freire demonstra a importância de o professor tornar-se profissional. Sem heroísmos e sem vitimismos, o professor para Freire é, acima de tudo, um profissional que atua no mundo para transformá-lo. Assim, segundo esse autor, o professor é absolutamente envolvido com seu contexto e busca por meio do diálogo a construção de uma educação como prática da liberdade. Para isso, o envolvimento com os alunos e com sua própria profissão é fundamental. Contra a neutralidade inexistente e a favor de uma práxis transformadora, compreendemos que o professor em Freire é fundamentalmente um profissional que, parafraseando Nietzsche é, sobretudo, "bumano, demasiado humano".

\section{Referências}

FREIDSON, E. Renascimento do profissionalismo. São Paulo: Edusp, 1998.

FREIRE, P. A Educação na cidade. São Paulo: Cortez, 1991.

FREIRE, P. Conscientização: teoria e prática da libertação: uma introdução ao pensamento de Paulo Freire. São Paulo: Cortez \& Moraes, 1980.

FREIRE, P. Pedagogia da Autonomia: saberes necessários à prática educativa. São Paulo: Paz e Terra, 1996.

FREIRE, P. Pedagogia da Esperança: um reencontro com a pedagogia do oprimido. São Paulo: Paz e Terra, 1992.

FREIRE, P. Pedagogia da Indignação: cartas pedagógicas e outros escritos. São Paulo: Editora Unesp, 2000.

FREIRE, P. Pedagogia do Oprimido. 11. ed. Rio de Janeiro: Paz e Terra, 1982.

FREIRE, P. Política e educação: ensaios. 5. Ed. São Paulo, Cortez, 2001. 
FREIRE, P. Professora sim, tia não: cartas a quem ousa ensinar. São Paulo: Olho Dágua, 1993.

FREIRE, P. Educação como prática de liberdade. Rio de Janeiro: Paz e Terra, 1967.

FREIRE, P.; SHOR, I. Medo e ousadia. O cotidiano do professor. Rio de Janeiro: Paz e Terra, 1986.

GAUTHIER, C.; MARTINEAU, S.; DESBIENS, J.F.; MALO, A.; SIMARD, D. Por uma Teoria da Pedagogia: Pesquisas Contemporâneas sobre o Saber Docente. Ijuí: Unijuí, 2013.

GADOTTI, M. A escola e o professor: Paulo Freire e a paixão de ensinar. São Paulo: Publisher Brasil, 2007.

HOLMES GROUP. Tomorrow's Teachers: a Report of the Holmes Group. East Lansing, MI: Holmes Group, 1986.

SCHÖN, D.A. The Reflective Practitioner: How Professionals Think in Action. EUA: Basic Books, 1983.

TARDIF, M. A profissionalização do ensino passados trinta anos: dois passos para a frente, três para trás. Educação e Sociedade, São Paulo, v.34, n.123, p. 551-571, abr./jun. 2013.

TARDIF, M.; LESSARD, C.; LAHAYE, L. Os professores face ao saber: um esboço de uma problemática do saber docente. Teoria e Educação, Porto Alegre, n. 4, v. 1, p. 215-233, 1991.

TARDIF, M. Saberes docentes e formação profissional. Petrópolis: Vozes, 2012a. $13^{\mathrm{a}}$ ed. 